necessary concomitant supportive therapy must continue. However, the necessity and desirability of treating all patients with AML with aggressive chemotherapy has been questioned. ${ }^{4}$ We were impressed with the ease with which early control of the disease was achieved without upset to the patients. Expensive supportive therapy was not necessary and this treatment allowed early discharge from hospital. If our findings are confirmed by further experience we would suggest that this type of regimen might have a place in the initial treatment with the aim of producing good partial remission and a return of the patient to reasonable health. From consideration of psychological, physical, and family factors patients could then be assessed for suitability for more aggressive intensive cytotoxic therapy. Whether the initial therapy would influence the incidence of complete remissions or the duration of survival remains to be answered. We feel that further study of the use of razoxane/cytarabine in $A M L$ is justified.

D SHAW

G RANKEN TUDHOPE

University Department of Pharmacology

and Therapeutics,
Ninewells Hospital,
Dundee

${ }^{1}$ Hellman, K, et al, Current Chemotherapy. Proceedings of the 10th International Congress of Chemotherapy, Zurich. Washington,

${ }^{2}$ Gale, R P, and Cline, M J, Lancet, 1977, 1, 497.

${ }^{3}$ Rees, J K H, et al, British fournal of Cancer, 1977,

4 Burge, P S, et al, Lancet, 1975, 2, 621.

\section{Maternal nutrition and infant birth weight}

SIR,-Perhaps I could reply to the criticisms of Mr M D G Gillmer (29 July, p 353) on our paper "Maternal and fetal nutrition in south India" (10 June, $p$ 1517). Our study involved one visit to each mother shortly after birth. A more elaborate study including observation throughout pregnancy has been undertaken in Vellore by Professor P S S Rao and his colleagues. This involved simple anthropometric measurements collected by non-medical staff. We felt that it would be valuable to study infant anthropometric measurements collected by one medical observer in an internationally acceptable way. We also studied maternal skinfold thickness. This measurement does not have the interpretational problems secondary to oedema of maternal weight measurements and maternal weight gain. It is also simple to perform and is acceptable to ordinary Indian women. There is no evidence that the nutritional patterns of these women change during pregnancy and therefore triceps skinfold thickness reflects nutrition as well as any simple measurement could do.

There were indeed maternal height differences between our paying and non-paying groups. Our results on the whole series, however, show correlation between maternal skinfold thickness and all infant measurements, whereas maternal height was correlated only with infant weight and length. It is therefore unlikely that the social class difference in infant size can be explained by maternal height variation alone.

Our study was limited by the length of time of my fellowship in India. It was also limited by the very different obstetric and paediatric climate in Britain compared with that of
India, where the majority of infants are delivered outside hospitals. Nevertheless, we studied a population in which maternal malnutrition is common and in which there was maternal smoking. This would be impossible in Britain. We believe that the conclusion we reached that the nutrition of the mother affects the nutrition of the baby is valid.

Llandough Hospital,
Penarth, S Glamorgan

J R SIBERT

\section{Intrathecal penicillin}

SIR,-We are perturbed whenever we hear of a death as a result of intrathecal injection of excessive amounts of benzylpenicillin. It appears that some clinicians are unaware of the neurotoxic effects of penicillin despite coverage of the subject in textbooks and in our data sheet.

After intravenous or intramuscular administration and in the absence of meningeal inflammation little penicillin enters the cerebrospinal fluid owing to the blood-brain barrier. However, even in this situation very large doses systemically (as are sometimes used in the treatment of bacterial endocarditis) or in severe renal failure doses above 6 megaunits daily ${ }^{1}$ can produce encephalopathy with convulsions.

Intrathecal injection bypasses the safeguard afforded by the blood-brain barrier and it is imperative that only a small dose be given. The usual dose for adults is $6 \mathrm{mg}$ (10000 units) dissolved in $10 \mathrm{ml}$ of sodium chloride injection $B P$ and injected slowly once daily. For infants and children $0.1 \mathrm{mg}$ (170 units) per $\mathrm{kg}$ body weight, diluted appropriately, is recommended.

F C Woop Senior Information Officer C DASH

Greenford, Middx Head of Medical Department, 'Beeley, L, Prescribers' fournal, 1977, 17, 1.

\section{Misuse of hypnosis}

SIR,-Dr H B Gibson should not take exception to my words (30 September, $p$ 957). The policy of the British Society of Medical and Dental Hypnosis is to teach hypnosis to doctors and dentists and to psychologists with a higher degree in psychology and working in the field of research or in hospital practice within a psychiatric unit.

Additionally, I need hardly remind $\mathrm{Dr}$ Gibson that I was one of the original supporters of his idea of a British Society of Experimental and Clinical Hypnosis for membership by those who fall within the latter category. The term "lay" refers to those who set themselves up as therapists without such qualifications and to stage performers.

I would refer to point (5) in my letter (19 August, p 571), which states: "The use of hypnosis is a psychotherapy and as such should only be used by those properly trained...."

D WAXMAN President, Section of Medical and Dental Hypnosis,
Royal Society of Medicin

\section{Health Service Commissioner and the} Rhyl case

SIR,-Now that the Select Committee on the Parliamentary Commissioner, in its Fifth Report, has expressed confidence in the Health Service Commissioner's handling of the "inhuman" Rhyl case hospital doctors have some idea of what can happen when complaints are made against them.

A senior house officer at Rhyl sent a patient 103-years-old back to a local authority home at 2 am on 29 November 1976 after determining that she had sustained no fractures in a fall at that home. The ambulance was diverted to deal with an urgent case and her departure delayed for 50 minutes. She died on, or shortly after, arrival at the residential home. The written complaint about her discharge arrived on 13 December, but "owing to a misunderstanding" the views of the doctor on the complaint were not obtained. The doctor left the country early in 1977 before the senior consultant surgeon had had "an opportunity to discuss with him the complaint about the handling of the case." The Health Service Commissioner investigated the case without interviewing or contacting the doctor. The health authority did not contact the doctor when the commissioner's draft was submitted to it for comment. The commissioner's description of the decision to discharge the patient at 2 am as "inhuman" was then published.

The NHS Act requires the commissioner to "afford to any other person who is alleged in the complaint to have taken or authorised the action complained of, an opportunity to comment on any allegation contained in the complaint." Because the doctor was not "named in the complaint" the commissioner said he was not under a legal duty to give that opportunity.

Following publication of the commissioner's report the health authority embarked on another investigation and, over one year after the events, at last, on 5 January 1978, sent the doctor the letter of complaint, the hospital medical records, and part of the commissioner's report and asked four specific questions to which the doctor replied on 10 January 1978. The authority established that the patient had repeatedly asked to go back to the home but did not ask the doctor whether he knew that and took it into consideration.

If a court of law or a tribunal were to deny a defendant or respondent the opportunity to defend himself its decisions would certainly be quashed by a higher court. This is what the Select Committee might have been expected to do. Instead, they listened to evidence from eight "witnesses," none of whom had any first-hand knowledge of the events of 29 November 1976, and then confirmed the decision. Why ? Their reasons seem to be:

(1) "Res ipsa loquitur"-the thing speaks for itself and admits no defence.

(2) Having made the clinical decision that the patient was fit to go, the doctor should have made an administrative decision to detain her till the morning because of her age.

(3) As to her own wish to go home, there was no evidence that the doctor took her wishes into consideration-whether he did or did not was not one of the four questions sent to him by the health authority-and in any case the wishes of a centenarian patient do not deserve great emphasis.

(4) The consultant (who had not discussed the complaint with the doctor) said he 